Article

\title{
Electron-Beam-Induced Current and Cathodoluminescence Study of Dislocations in $\mathrm{SrTiO}_{3}$
}

\author{
Wei Yi ${ }^{1}$, Jun Chen ${ }^{2, *(D)}$ and Takashi Sekiguchi ${ }^{1,2}$ \\ 1 National Institute for Materials Science, Tsukuba 305-0044, Japan; YI.Wei@nims.go.jp (W.Y.); \\ sekiguchi.takashi.fp@u.tsukuba.ac.jp (T.S.) \\ 2 Faculty of Pure and Applied Sciences, University of Tsukuba, Tsukuba 305-8577, Japan \\ * Correspondence: CHEN.Jun@nims.go.jp; Tel.: +81-29-860-4298
}

Received: 30 July 2020; Accepted: 20 August 2020; Published: 21 August 2020

\begin{abstract}
Electron-beam-induced current (EBIC) and cathodoluminescence (CL) have been applied to investigate the electrical and optical behaviors of dislocations in $\mathrm{SrTiO}_{3}$. The electrical recombination activity and defect energy levels of dislocations have been deduced from the temperature-dependent EBIC measurement. Dislocations contributed to resistive switching were clarified by bias-dependent EBIC. The distribution of oxygen vacancies around dislocations has been obtained by CL mapping. The correlation between switching, dislocation and oxygen vacancies was discussed.
\end{abstract}

Keywords: $\mathrm{SrTiO}_{3}$; dislocation; $\mathrm{EBIC} ; \mathrm{CL}$

\section{Introduction}

The perovskite oxides, especially $\mathrm{SrTiO}_{3}$ and its related oxides, have attracted much attention because of their dielectric and ferroelectric properties. The oxygen vacancies $\left(\mathrm{V}_{\mathrm{o}}\right)$ directly govern the bulk and interfacial properties of perovskites, including $\mathrm{V}_{\mathrm{o}}$ related dielectric relaxation and electrical conduction [1], n-type doping in $\mathrm{SrTiO}_{3}$ [2], as well as the introduction of two-dimensional electron gas at the interface of $\mathrm{SrTiO}_{3} / \mathrm{LaAlO}_{3}[3,4]$. With the rising interest in resistance switchable oxides, the behavior of $V_{o}$ has again become the highlight of the study on switching mechanisms [5-7]. The switching mechanism has been interpreted either by the interface model due to charge trapping and detrapping or the filament model based on $V_{o}$ migration [8-11]. The distribution and diffusion kinetics of $\mathrm{Vo}$ in single-crystal $\mathrm{SrTiO}_{3}$ has been investigated by the combination of isotope exchange and time-of-flight secondary ion mass spectrometry, and it is indicated that the Gibbs formation energy of Vo at the interface is lower than in the bulk [12].

On the other hand, the presence of crystallographic defects such as dislocations would also affect the distribution of $\mathrm{V}_{\mathrm{o}}$. In present $\mathrm{SrTiO}_{3}$ crystals, there are still high-density dislocations in the order of $10^{6} \sim 10^{8} \mathrm{~cm}^{-2}$. Hence, the interaction between Vo and dislocations are of principal importance to the performances of resistive switching devices. The role of dislocations on the defect chemistry and oxide ion transport properties has been assessed by atomistic simulations with lower formation energies $\mathrm{V}_{\mathrm{O}}$ at dislocation cores [13]. To investigate the switching activities of dislocations in $\mathrm{SrTiO}_{3}$, electron-beam-induced current (EBIC) has been applied to metal/SrTiO ${ }_{3}$ Schottky contacts. For instance, in non-doped (100) $\mathrm{SrTiO}_{3}$ crystal, a transition of EBIC contrast of dislocation arrays from dark to bright was discovered when subjected to electrical stress, and it was explained that the change of EBIC contrast is due to $\mathrm{V}_{\mathrm{o}}$ diffusion along dislocations [14]. Our group has performed systematic EBIC studies of differently $\mathrm{Nb}$-doped (111) and (100) $\mathrm{SrTiO}_{3}$ crystals [15,16], and we found that dislocations can act as either recombination centers or conduction paths depending on their character, bias condition 
and $\mathrm{Nb}$ doping concentrations. These studies also suggested that not all the dislocations contribute to the switching phenomenon.

However, there is still a lack of an experiment method to directly identify the local distribution of $\mathrm{V}_{\mathrm{o}}$ around dislocations. It has been confirmed that $\mathrm{V}_{\mathrm{o}}$ in $\mathrm{SrTiO}_{3}$ would emit light under beam or light injection [17-20], the emission is attributed to the radiative recombination of carriers via defect levels introduced by $\mathrm{V}_{\mathrm{o}}$. As many studies suggested, dislocations can modulate the distribution of oxygen vacancies; recently, we have applied cathodoluminescence (CL) to non-doped $\mathrm{SrTiO}_{3}$, and enhanced $\mathrm{V}_{\mathrm{o}}$-related luminescence from certain dislocations was found [21].

In the study, we attempt to clarify the electrical activities of dislocations in $\mathrm{Nb}$-doped $\mathrm{SrTiO}_{3}$ by temperature-dependent EBIC measurement. According to the temperature-dependence of EBIC contrast, the energy levels of defects would be known. Generally, shallow level defects become EBIC active at lower temperatures while deep level defects are active at room temperature. This dependence is explained based on Shockley-Read-Hall (SRH) statistics [22], and thus temperature-dependent EBIC has been extensively applied in the study of extended defects in Si-based materials [23-26] as well as wide-gap semiconductor materials [27]. However, for dislocations in $\mathrm{SrTiO}_{3}$, so far as we know there is no temperature-dependent EBIC performed. Furthermore, a combinational EBIC and CL study of the electrical/optical behaviors of dislocations in $\mathrm{SrTiO}_{3}$ will be carried out. The correlation between dislocation defect level, resistive switching and $\mathrm{V}_{\mathrm{o}}$ distribution will be investigated.

\section{Materials and Methods}

Commercially available n-type $\mathrm{Nb}$-doped $\mathrm{SrTiO}_{3}$ single crystals grown by Verneuil process (SHINKOSYA, Yokohama, Japan) were used in this study. The doping concentration of $\mathrm{Nb}$ was about $0.01 \%$ by weight, corresponding to a carrier concentration of $2 \sim 4 \times 10^{18} \mathrm{~cm}^{-3}$. For the EBIC experiment, in order to obtain an atomically flat surface for the fabrication of better Schottky contact, the specimens were first annealed at $1000{ }^{\circ} \mathrm{C}$ in air for $2 \mathrm{~h}$. Schottky contacts were prepared by e-beam deposition of $\mathrm{Pt}$ with a thickness of $20 \mathrm{~nm}$ on the top surface, and Ohmic contacts were prepared by e-beam deposition of $\mathrm{Al}$ with a thickness of $30 \mathrm{~nm}$ on the back. EBIC measurements were carried out by a JEOL JSM-7600F field emission scanning electron microscope (FE-SEM) (JEOL, Tokyo, Japan) with the accelerating voltage of $7 \mathrm{kV}$. The beam current is about $250 \mathrm{pA}$. Kleindiek micromanipulators installed inside the SEM chamber were used for the electrical connections for EBIC measurement and bias voltage applying. The temperature was varied from $120 \mathrm{~K}$ to room temperature by a cooling stage. To obtain an EBIC contrast-temperature profile, images were taken every $10 \mathrm{~K}$ steps. The EBIC contrast $C$ is defined by:

$$
\mathrm{C}=100 \% \times\left(\mathrm{I}_{\mathrm{B}}-\mathrm{I}_{\mathrm{d}}\right) / \mathrm{I}_{\mathrm{b}}
$$

where $\mathrm{I}_{\mathrm{b}}$ and $\mathrm{I}_{\mathrm{d}}$ are the EBIC currents collected at the background and dislocation, respectively. For CL observation, bare $\mathrm{SrTiO}_{3}$ specimens which had undergone same annealing procedure were used. CL measurement was conducted by a HORIBA MP32 CL system (HORIBA, Kyoto, Japan) attached to a Hitachi SU6600 FE-SEM (Hitachi High-Tech, Tokyo, Japan). The accelerating voltage was $7 \mathrm{kV}$ same as that of EBIC observation. The temperature was set at $80 \mathrm{~K}$ and $300 \mathrm{~K}$, respectively.

\section{Results and Discussion}

EBIC images were taken in the temperature range of $120 \sim 300 \mathrm{~K}$, and in this temperature range the EBIC contrast of dislocations increased with rising temperature. Representative EBIC images taken at low $(120 \mathrm{~K})$, medium $(200 \mathrm{~K})$ and room temperature $(300 \mathrm{~K})$ were demonstrated here. Figure 1a-d shows the secondary electron (SE) and temperature-dependent EBIC images of dislocations in (111) $\mathrm{SrTiO}_{3}$. The in-plane orientations were indicated by the Thompson tetrahedron in Figure 1a. In the EBIC image at $120 \mathrm{~K}$, there were straight and curved/tangled lines with gray contrast. The straight lines were along $<112>$ directions. The straight lines are related to slip dislocations, and the curved/tangled lines are dislocations interacted with each other or in cluster. Bright EBIC contrast was observed around 
these curved and tangled dislocations when temperature below $200 \mathrm{~K}$. When temperature increased to $200 \mathrm{~K}$, the EBIC contrast of most dislocations showed no obvious change, except for the tangled dislocations in the upright showed stronger dark contrast than the others. The bright EBIC contrast was still visible around the curved/tangled dislocations at this temperature. When temperature further increased to $300 \mathrm{~K}$, the dislocations became more significant with dark contrast. The EBIC contrast varied greatly among different dislocations, i.e., the curved/tangled dislocations exhibited strong dark contrast than the slip lines. The bright EBIC contrast around the curved/tangled dislocations became invisible at $300 \mathrm{~K}$.
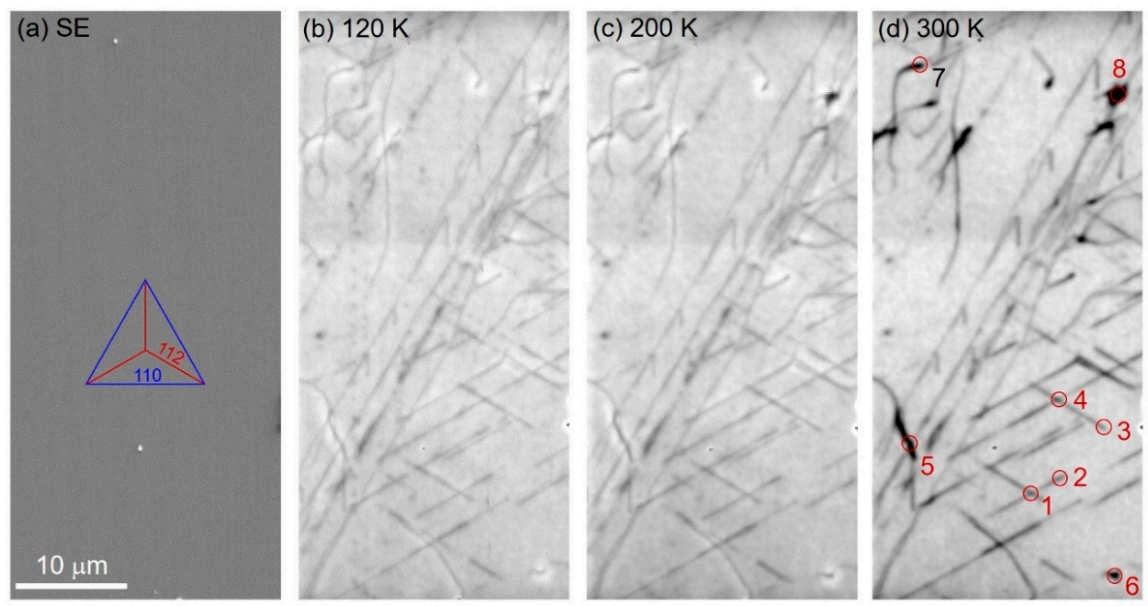

Figure 1. SE and temperature-dependent electron-beam-induced current (EBIC) images of dislocations in (111) $\mathrm{SrTiO}_{3}$. (a) SE; (b) EBIC $120 \mathrm{~K}$; (c) EBIC $200 \mathrm{~K}$; (d) EBIC $300 \mathrm{~K}$. Site 1-4 are dislocations slips and site $5-8$ are tangled dislocations.

To describe the recombination activity and defect levels, we plotted the variation of EBIC contrast of typical dislocations (denoted as sites 1 8 in Figure 1d) with respect to temperature as shown in Figure 2. According to the EBIC contrast statistics, it is clear to see that the EBIC contrast of all dislocations increased monotonically with temperature. At $120 \mathrm{~K}$, the EBIC contrast of all dislocations was weak about 5 10\%. The EBIC contrast of tangled dislocations (site 8) quickly increased from $150 \mathrm{~K}$, and became extremely strong $(\sim 55 \%)$ at $300 \mathrm{~K}$. The EBIC contrast of the curved dislocations (sites 5 7) started to increase from $200 \mathrm{~K}$ and was about $30 \%$ at $300 \mathrm{~K}$. The EBIC contrast of the straight slip lines (sites 1 4) gradually increased with temperature and was $10 \sim 20 \%$ at $300 \mathrm{~K}$.

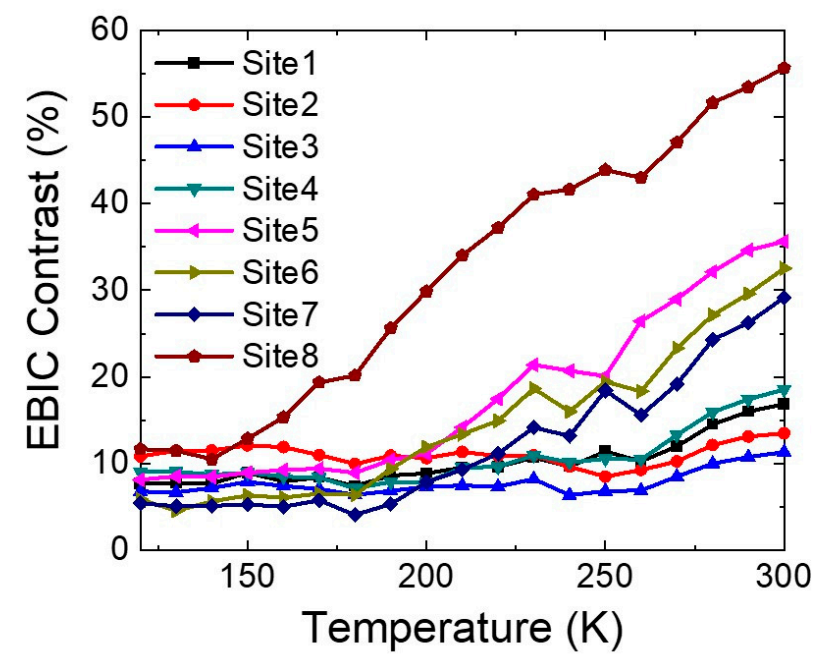

Figure 2. Variation of EBIC contrast of dislocation related defects with respect to temperature. The different sites were denoted by 1 8 in Figure $1 \mathrm{~d}$. 
EBIC contrast reflects the recombination activity of minority carries via a defect level, and the temperature-dependence of EBIC contrast is strongly dependent on the position of defect level [26]. Shallow-level defects show weak contrast at room temperature and strong contrast at low temperature, which is due to the change in the occupation of shallow level caused by the shift in the Fermi level with temperature. On the contrary, deep-level defects show stronger contrast at room temperature. This is because that deep level is far from the Fermi level and the occupation of deep level is not greatly affected by the shifts in Fermi level with temperature. Hence, the EBIC contrast of deep-level defect shows a temperature dependence of the form $C \propto \mathrm{T}^{1 / 2}$ (temperature dependence of the thermal velocity of carriers).

Based on temperature-dependent EBIC results, we can discuss the recombination activity of dislocations in $\mathrm{SrTiO}_{3}$. The EBIC contrast of all dislocations at room temperature tends to be stronger than that at low temperatures, which suggests that the dislocations in $\mathrm{SrTiO}_{3}$ act as strong recombination centers for minority carriers. The contrast-temperature characteristics indicate that dislocations are accompanied with deep levels, especially the tangled dislocations with more deeper levels. The bright EBIC contrast around the tangled dislocations is due to the formation of denuded zones by impurity gettering. Dislocation clusters could act as strong gettering sites of impurities and/or point defects, and thus to form a region with comparatively longer diffusion length of minority carrier around the defects. A similar phenomenon has been found in our previous EBIC study of grain boundaries in contaminated multicrystalline $\mathrm{Si}$ [25]. The appearance of denuded zones at low temperatures is due to the smaller carrier diffusion length at low temperatures. The presence of denuded zones around dislocation clusters could be explained in terms of gettering effect. On the other hand, the dislocation clusters may also act as a sink of oxygen vacancies and result in the formation of denuded zones. So far, there are very few reports on the background impurities in $\mathrm{SrTiO}_{3}$. An early report by Chan et al. [28] suggested that there are over 18 unintentional impurities ( $\mathrm{Si}, \mathrm{Fe}, \mathrm{Mg}, \mathrm{Cl}, \mathrm{C}$, etc.) in $\mathrm{SrTiO}_{3}$ crystals. At present, it is difficult to figure out the level of impurities decorated around dislocations due to the limitation of analysis techniques.

Next, EBIC studies under bias voltages were conducted to find out the active dislocations for resistive switching. Figure 3a,b shows the room-temperature EBIC images of dislocations taken under zero bias $(0 \mathrm{~V})$ and negative bias voltage $(-2 \mathrm{~V})$ in (111) $\mathrm{SrTiO}_{3}$. At $0 \mathrm{~V}$, all the dislocations were observed with dark EBIC contrast. At $-2 \mathrm{~V}$, bright contrast became visible around and/or at the straight lines related to slip dislocations along $<112>$ directions. However, no bright contrast was found near the curved/tangled dislocations. The narrowing of line contrast under the negative bias indicated that the band bending had suppressed the carrier diffusion and recombination.

(a) $\mathrm{EBIC}(0 \mathrm{~V})$

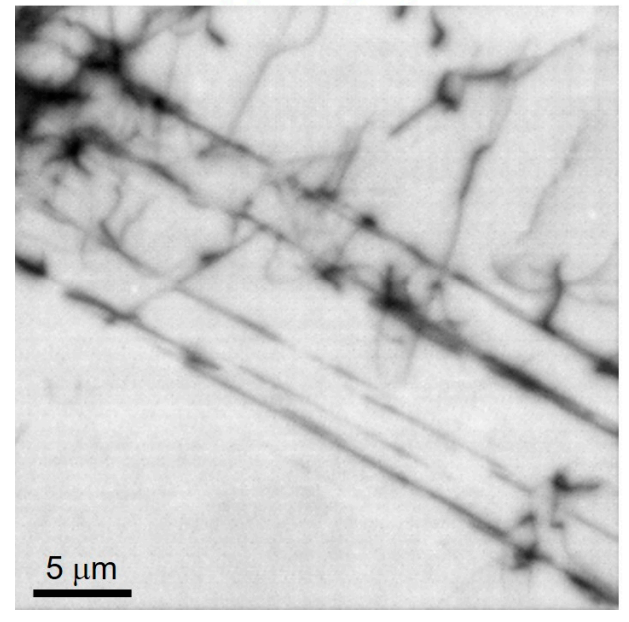

(b) $\operatorname{EBIC}(-2 \mathrm{~V})$

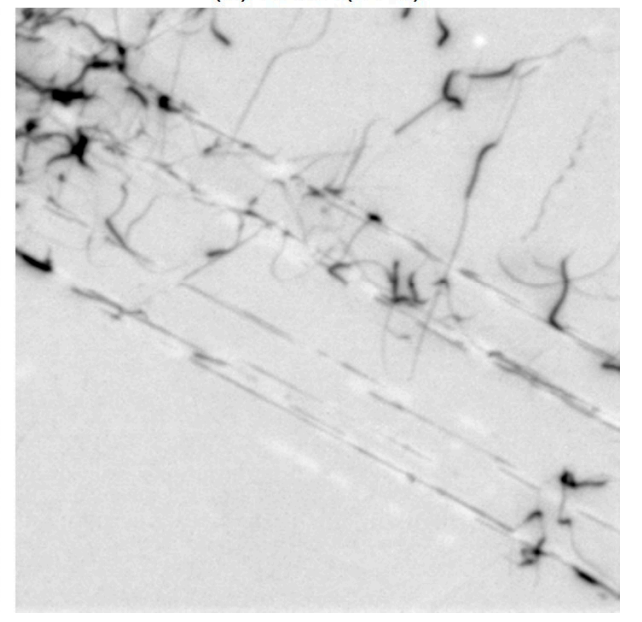

Figure 3. Room-temperature EBIC images of dislocations in (111) $\mathrm{SrTiO}_{3}$ taken at different bias voltages. (a) $0 \mathrm{~V} ;(\mathbf{b})-2 \mathrm{~V}$. 
The origin of EBIC contrast changing from dark to bright under negative bias voltage is related to the change of depletion layer width under biasing compared to the depth of carrier generation by e-beam injection. The depletion layer width of the $\mathrm{Pt} / \mathrm{SrTiO}_{3}$ Schottky was about $130 \mathrm{~nm}$ at zero bias and $280 \mathrm{~nm}$ at $-2 \mathrm{~V}$. The depth of carrier generation by e-beam injection is about $200 \mathrm{~nm}$ at the accelerating voltage of $7 \mathrm{kV}$. When carrier generation is mainly in the bulk region (below the depletion layer), dislocations can act as active recombination centers and show dark EBIC contrast. When biased at $-2 \mathrm{~V}$, the width of depletion layer increases and carrier generation is mainly located inside the depletion layer, the recombination process is greatly suppressed and the enhanced transportation of minority carriers via dislocations could be observed.

The bias-dependent EBIC results suggest that some dislocations could act as conduction paths for resistive switching. As for the origin of bright contrast, there are several explanations, such as the migration of $\mathrm{V}_{\mathrm{O}}$ along dislocations under bias voltage or carrier tunneling through empty levels associated with these dislocations. It is quite interesting to find that bright EBIC contrast appeared either at low temperatures or under bias voltage. However, the origins of these two bright contrasts are different. The bright contrast around tangled dislocations is related to impurity gettering, while the bright contrast which appeared under negative bias voltages could be explained by the enhanced carrier transport via dislocations inside the depletion region.

To confirm the distribution of Vo around dislocations, CL image and spectrum were taken at $80 \mathrm{~K}$ and $300 \mathrm{~K} . \mathrm{V}_{\mathrm{o}}$ related emission $(\sim 2.8 \mathrm{eV})$ was detected at both temperatures. Hence, we performed CL mapping of dislocations in $\mathrm{SrTiO}_{3}$ at an emission energy of $2.8 \mathrm{eV}$. Figure $4 \mathrm{a}$, b shows the monochromatic CL images of dislocations taken at $80 \mathrm{~K}$ and $300 \mathrm{~K}$ in (110) $\mathrm{SrTiO}_{3}$, respectively. For this sample, the emission from background region is not homogenous, suggesting an inhomogeneous distribution of $\mathrm{V}_{\mathrm{o}}$. Dislocations were observed with dark contrast in the room-temperature $\mathrm{CL}$ image, and became faint at $80 \mathrm{~K}$. The CL appearance of dislocations at low- and room-temperature is consistent with the temperature-dependent EBIC study. The recombination via dislocations is non-radiative and associated with deep levels. However, it should be noted that bright CL contrast appeared at some of the straight slip lines.

(a) $\mathrm{CL}(80 \mathrm{~K})$

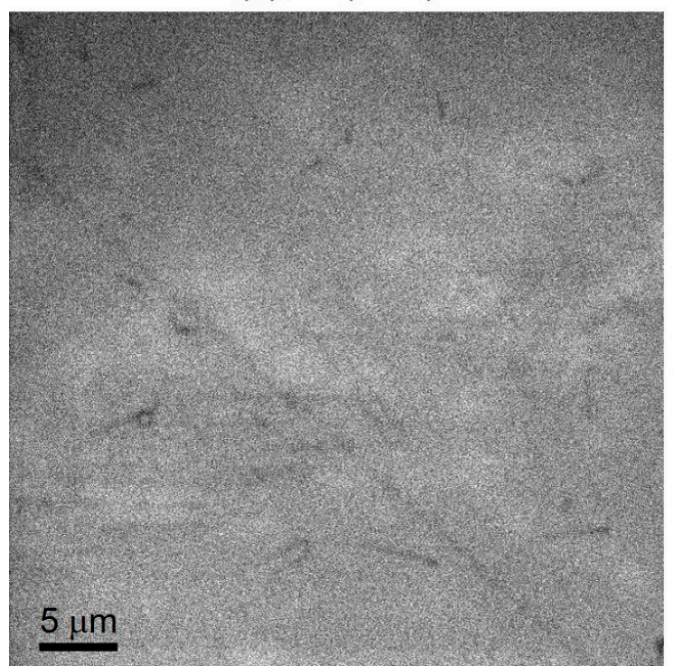

(b) $\mathrm{CL}(300 \mathrm{~K})$

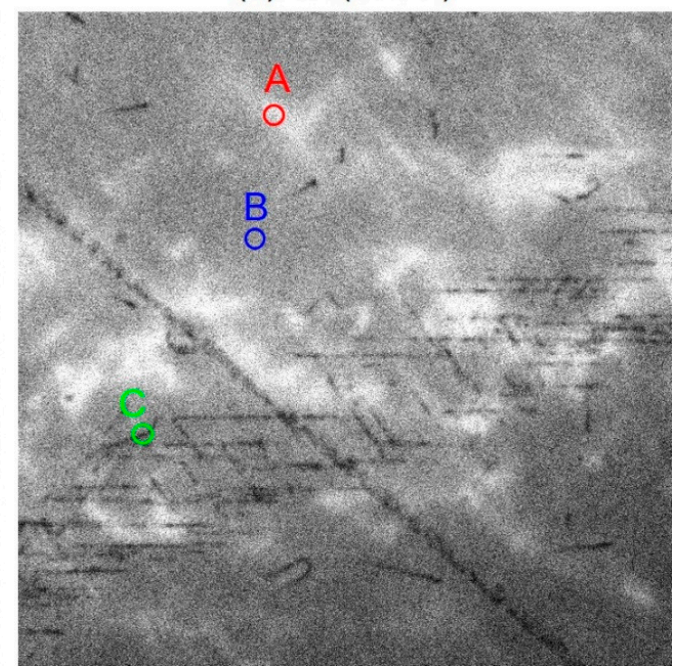

Figure 4. Monochromatic cathodoluminescence (CL) images of dislocations in (110) oriented $\mathrm{SrTiO}_{3}$ taken at the emission energy of $2.8 \mathrm{eV}$. (a) $80 \mathrm{~K}$ and (b) $300 \mathrm{~K}$. Site A-C: A-straight line with bright contrast; B-background; C-curved dislocation with dark contrast.

Figure 5 shows the room temperature CL point spectra from three different sites marked in Figure $4 \mathrm{~b}$. Site A is close to a straight line with bright CL contrast, Site B is the background, and Site C is a curved dislocation with dark CL contrast. The CL intensity was normalized to the background 
intensity. It was found that CL spectrum from the different regions showed similar a broad peak centered at $2.8 \mathrm{eV}$. The peak intensity of Site A is about 1.3 times higher than that of the background, while the peak intensity at the curved dislocation (Site C) slightly decreased.

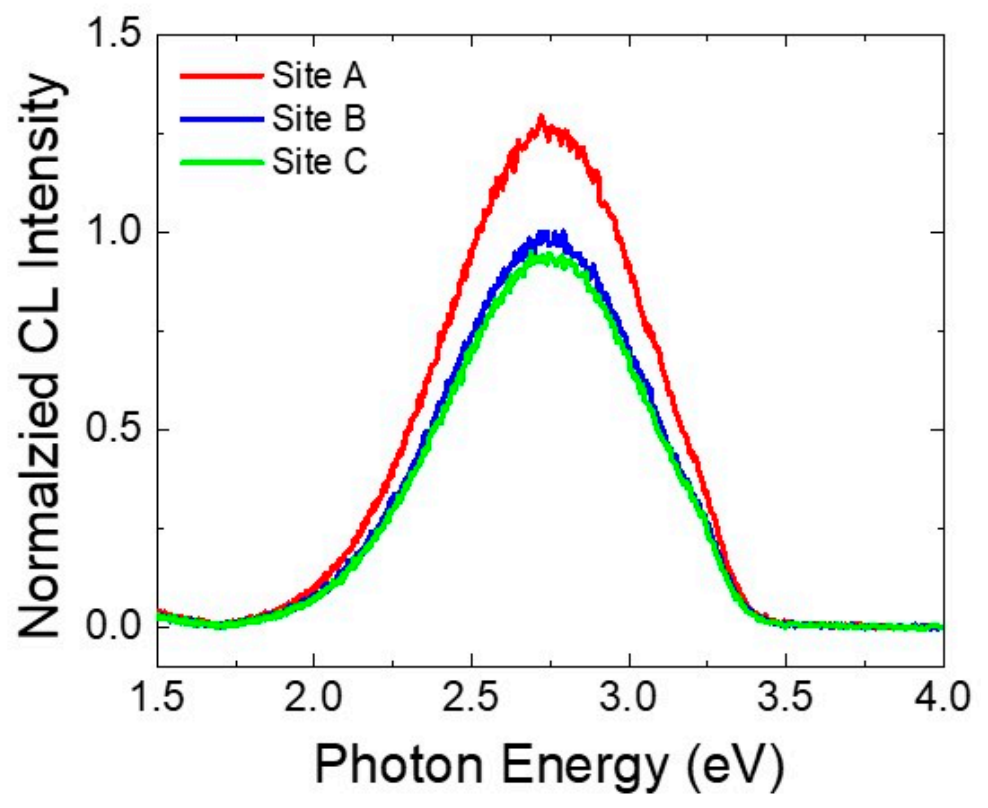

Figure 5. Room temperature CL spectra of different sites denoted as A-C in Figure 4b.

The bight CL contrast detected from slip lines suggests the enrichment of $\mathrm{V}_{\mathrm{o}}$ at these dislocations. Correspondingly, the bright EBIC contrast of dislocations under bias voltage could be related to the migration of $\mathrm{V}_{\mathrm{o}}$ along dislocations. The difference between individual and tangled dislocations may be explained from the viewpoint of diffusion path for $\mathrm{V}_{\mathrm{o}}$ migration. An individual dislocation, when it is smooth and perpendicular to the surface, could act as a fast diffusion path for $\mathrm{V}_{\mathrm{o}}$. On the contrary, the diffusion $\mathrm{V}_{\mathrm{o}}$ would be difficult through tangled dislocations. $\mathrm{CL}$ results have indicated that some dislocations in $\mathrm{SrTiO}_{3}$ would modulate the distribution of $\mathrm{V}_{\mathrm{o}}$. However, bright CL contrast was also observed in the regions without dislocations. It is speculated that the distribution of $\mathrm{V}_{\mathrm{o}}$ would be affected by a variety of factors. In addition to dislocations, there may be other factors such as strain and impurities. Future studies are needed to clarify this.

\section{Conclusions}

This paper reported temperature-dependent EBIC and CL studies of dislocations in Nb-doped $\mathrm{SrTiO}_{3}$. The major findings include the following: (1) EBIC indicates that dislocations in $\mathrm{SrTiO}_{3}$ are electrically active at room temperature and act as recombination centers of minority carriers. In particular, the tangled dislocations are strong recombination centers associated with deep levels and denuded zones are formed around them; (2) dislocations arrayed along slip lines are active for resistive switching, while curved and tangled dislocations are not; (3) CL suggests that nonradiative recombination via dislocations is strong at room temperature, which is in good correlation with EBIC. An enrichment of $V_{o}$ along dislocation slips has been found.

Author Contributions: Conceptualization, J.C. and T.S.; methodology, W.Y. and J.C.; writing-original draft preparation, W.Y. and J.C.; writing-review and editing, J.C. and T.S.; funding acquisition, J.C. All authors have read and agreed to the published version of the manuscript.

Funding: This research was funded by JSPS KAKENHI, grant number $18 \mathrm{~K} 04248$.

Acknowledgments: We are grateful to HORIBA Ltd. for the technique support in cathodoluminescence.

Conflicts of Interest: The authors declare no conflict of interest. 


\section{References}

1. Ang, C.; Yu, Z.; Cross, L.E. Oxygen-vacancy-related low-frequency dielectric relaxation and electrical conduction in $\mathrm{Bi}_{\mathrm{S}} \mathrm{SrTiO}_{3}$. Phys. Rev. B 2000, 62, 228-236. [CrossRef]

2. Ohtomo, A.; Hwang, H.Y. Growth mode control of the free carrier density in $\mathrm{SrTiO}_{3-\delta}$ films. J. Appl. Phys. 2007, 102, 083704. [CrossRef]

3. Kalabukhov, A.; Gunnarsson, R.; Börjesson, J.; Olsson, E.; Claeson, T.; Winkler, D. Effect of oxygen vacancies in the $\mathrm{SrTiO}_{3}$ substrate on the electrical properties of the $\mathrm{LaAlO}_{3} / \mathrm{SrTiO}_{3}$ interface. Phys. Rev. B 2007, 75, 121404. [CrossRef]

4. Siemons, W.; Koster, G.; Yamamoto, H.; Harrison, W.A.; Lucovsky, G.; Geballe, T.H.; Blank, D.H.; Beasley, M.R. Origin of charge density at $\mathrm{LaAlO}_{3}$ on $\mathrm{SrTiO}_{3}$ heterointerfaces: Possibility of intrinsic doping. Phys. Rev. Lett. 2007, 98, 196802. [CrossRef] [PubMed]

5. Nian, Y.B.; Strozier, J.; Wu, N.J.; Chen, X.; Ignatiev, A. Evidence for an oxygen diffusion model for the electric pulse induced resistance change effect in transition-metal oxides. Phys. Rev. Lett. 2007, 98, 146403. [CrossRef]

6. Janousch, M.; Meijer, G.I.; Staub, U.; Delley, B.; Karg, S.F.; Andreasson, B.P. Role of oxygen vacancies in Cr-doped $\mathrm{SrTiO}_{3}$ for resistance-change memory. Adv. Mater. 2007, 19, 2232-2235. [CrossRef]

7. Yang, J.J.; Miao, F.; Pickett, M.D.; Ohlberg, D.A.A.; Stewart, D.R.; Lau, C.N.; Williams, R.S. The mechanism of electroforming of metal oxide memristive switches. Nanotechnology 2009, 20, 215201. [CrossRef]

8. Fujii, T.; Kawasaki, M.; Sawa, A.; Kawazoe, Y.; Akoh, H.; Tokura, Y. Electrical properties and colossal electroresistance of heteroepitaxial $\mathrm{SrRuO}_{3} / \mathrm{SrTi}_{1-x} \mathrm{Nb}_{x} \mathrm{O}_{3}(0.0002 \leq x \leq 0.02)$ Schottky junctions. Phys. Rev. $B$ 2007, 75, 165101. [CrossRef]

9. Li, J.Y.; Ohashi, N.; Okushi, H.; Haneda, H. Temperature dependence of carrier transport and resistance switching in $\mathrm{Pt} / \mathrm{SrTi}_{1-\mathrm{x}} \mathrm{Nb}_{\mathrm{x}} \mathrm{O}_{3}$ Schottky junctions. Phys. Rev. B 2011, 83, 125317. [CrossRef]

10. Szot, K.; Speier, W.; Bihlmayer, G.; Waser, R. Switching the electrical resistance of individual dislocations in single-crystalline $\mathrm{SrTiO}_{3}$. Nat. Mater. 2006, 5, 312-320. [CrossRef]

11. Sawa, A. Resistive switching in transition metal oxides. Mater. Today 2008, 11, 28-36. [CrossRef]

12. De Souza, R.A.; Metlenko, V.; Park, D.; Weirich, T.E. Behavior of oxygen vacancies in single-crystal $\mathrm{SrTiO}_{3}$ : Equilibrium distribution and diffusion kinetics. Phys. Rev. B 2012, 85, 174109. [CrossRef]

13. Marrocchelli, D.; Sun, L.; Yildiz, B. Dislocations in $\mathrm{SrTiO}_{3}$ : Easy to reduce but not so fast for oxygen transport. J. Am. Chem. Soc. 2015, 137, 4735-4748. [CrossRef] [PubMed]

14. Jiang, W.; Evans, D.; Bain, J.A.; Skowronski, M.; Salvador, P.A. Electron beam induced current investigations of $\mathrm{Pt} / \mathrm{SrTiO}_{3-\mathrm{x}}$ interface exposed to chemical and electrical stresses. Appl. Phys. Lett. 2010, 96, 092102. [CrossRef]

15. Chen, J.; Sekiguchi, T.; Li, J.Y.; Ito, S.; Yi, W.; Ogura, A. Investigation of dislocations in Nb-doped SrTiO 3 by electron-beam-induced current and transmission electron microscopy. Appl. Phys. Lett. 2015, 106, 102109. [CrossRef]

16. Chen, J.; Sekiguchi, T.; Li, J.Y.; Ito, S. Investigation of dislocations in $\mathrm{Nb}$-doped (100) $\mathrm{SrTiO}_{3}$ single crystals and their impacts on resistive switching. Superlattices Microstruct. 2016, 99, 182-185. [CrossRef]

17. Kan, D.; Terashima, T.; Kanda, R.; Masuno, A.; Tanaka, K.; Chu, S.; Kan, H.; Ishizumi, A.; Kanemitsu, Y.; Shimakawa, Y.; et al. Blue-light emission at room temperature from $\mathrm{Ar}^{+}$-irradiated $\mathrm{SrTiO}_{3}$. Nat. Mater. 2005, 4, 816-819. [CrossRef]

18. Bruno, F.Y.; Tornos, J.; Olmo, M.G.; Santolino, G.S.; Nemes, N.M.; Garcia-Hernandez, M.; Mendez, B.; Piqueras, J.; Antorrena, G.; Morellon, L.; et al. Anisotropic magnetotransport in $\mathrm{SrTiO}_{3}$ surface electron gases generated by $\mathrm{Ar}^{+}$irradiation. Phys. Rev. B 2011, 83, 245120. [CrossRef]

19. Lim, J.; Lee, Y.S.; Bu, S.D. Surface-direction dependence of the oxygen vacancy formation in $\mathrm{SrTiO}_{3}$ single crystals. Ceram. Int. 2018, 44, S93-S95. [CrossRef]

20. Lee, D.; Wang, H.W.; Noesges, B.A.; Asel, T.J.; Pan, J.B.; Lee, J.W.; Yan, Q.; Brillson, L.J.; Wu, X.; Eom, C.B. Identification of a functional point defect in $\mathrm{SrTiO}_{3}$. Phys. Rev. Mater. 2018, 2, 060403(R). [CrossRef]

21. Wang, P.; Yi, W.; Chen, J.; Ito, S.; Cui, C.; Sekiguchi, T. Oxygen vacancy migration along dislocations in $\mathrm{SrTiO}_{3}$ by cathodoluminescence. J. Phys. D Appl. Phys. 2019, 52, 475103. [CrossRef]

22. Shockley, W.; Read, W.T. Statistics of the recombination of holes and electrons. Phys. Rev. 1952, 87, 835-842. [CrossRef] 
23. Kusanagi, S.; Sekiguchi, T.; Shen, B.; Sumino, K. Electrical activity of extended defects and gettering of metallic impurities in silicon. Mater. Sci. Technol. 1995, 11, 685-690. [CrossRef]

24. Kveder, V.; Kittler, M.; Schröter, W. Recombination activity of contaminated dislocations in silicon: A model describing electron-beam-induced current contrast behavior. Phys. Rev. B 2001, 63, 115208. [CrossRef]

25. Chen, J.; Sekiguchi, T.; Yang, D.; Yin, F.; Kido, K.; Tsurekawa, S. Electron-beam-induced current study of grain boundaries in multicrystalline silicon. J. Appl. Phys. 2004, 96, 5490-5495. [CrossRef]

26. Kittler, M.; Seifert, W. Two types of electron-beam-induced current behaviour of misfit dislocations in $\mathrm{Si}(\mathrm{Ge})$ : Experimental observations and modelling. Mater. Sci. Eng. B 1994, 24, 78-81. [CrossRef]

27. Maximenko, S.I.; Freitas, J.A., Jr.; Myers-Ward, R.L.; Lew, K.-K.; VanMil, B.L.; Eddy, C.R., Jr.; Gaskill, D.K.; Muzykov, P.G.; Sudarshan, T.S. Effect of threading screw and edge dislocations on transport properties of 4H-SiC homoepitaxial layers. J. Appl. Phys. 2010, 108, 013708. [CrossRef]

28. Chan, N.-H.; Sharma, R.K.; Smyth, D.M. Nonstoichiometry in SrTiO . J. Electrochem. Soc. 1981, 128, $1762-1769$. [CrossRef]

(C) 2020 by the authors. Licensee MDPI, Basel, Switzerland. This article is an open access article distributed under the terms and conditions of the Creative Commons Attribution (CC BY) license (http://creativecommons.org/licenses/by/4.0/). 